\title{
WAVE-LENGTHS OF NEON
}

\author{
By Irwin G. Priest
}

Introduction.-The Io wave-lengths of neon presented in the accompanying table have been determined by the method of reflection fringes previously described in this Bulletin. ${ }^{1}$ Only minor changes of method and apparatus, mostly for convenience, have been made in this research. The lamps were of the high-voltage "vacuum" type and operated on a transformer circuit.

The probable errors of the final results are shown in Columns II and III of the table. They are all less than one part in ten million. The average probable error of the result of a single determination (usually involving to measurements of the order of interference) is about one part in eight or nine million. The average residual of the determinations relative to neon 5852 as standard is about o.oor $\mathrm{A}$, or one part in six million.

Basis and Reliability of the Results.-The ultimate reference standard to which these values are referred is the wave-length of cadmium red taken as 6438.4696 I. A. ${ }^{2}$ The value $\mathbf{5 8 5 2 . 4 8 6 2}$ I. A. for the bright yellow neon line is derived from our previous determination ${ }^{3}$ of this wave-length relative to cadmium red by

\footnotetext{
1 This Bulletin, 6, p. 573; I9II (Reprint No. 142).

2 Trans. Inter. Solar Union, 2, 20. Astrop. Jour., 32, 2I5; I9ro.

3 This Bulletin, 6, 599; I911.
} 


\section{TABLE I ${ }^{4}$}

\section{General Summary of Results}

\begin{tabular}{|c|c|c|c|c|c|c|}
\hline I & II & III & IV & $\mathbf{v}$ & vI & VII \\
\hline $\begin{array}{l}\text { Wave- } \\
\text { Lengths in } \\
\text { Interna- }\end{array}$ & \multicolumn{2}{|c|}{$\begin{array}{l}\text { Probable errors } b \text { rela- } \\
\text { tive to }\end{array}$} & \multirow{2}{*}{$\begin{array}{c}\text { Number of measurements } \\
\text { involved } c\end{array}$} & \multirow{2}{*}{$\begin{array}{l}\text { Average of ac- } \\
\text { cepted minus } \\
\text { average of } \\
\text { rejected } \\
\text { determinations }\end{array}$} & \multicolumn{2}{|c|}{$\begin{array}{c}\text { Difference be- } \\
\text { tween present } \\
\text { and former } \\
\text { determinations } d\end{array}$} \\
\hline $\begin{array}{c}\text { Ångström } \\
\text { Units } a\end{array}$ & $\begin{array}{l}\text { Neon yel- } \\
\text { low, } 5852\end{array}$ & $\begin{array}{l}\text { Cadmium } \\
\text { red, } 6438\end{array}$ & & & $\begin{array}{c}\text { Baly } \\
\text { minus } \\
\text { Priest }\end{array}$ & $\begin{array}{l}\text { Watson } \\
\text { minus } \\
\text { Priest }\end{array}$ \\
\hline 5852.4862 & & \pm 0.0003 & $1(5,5) ; 6(10,10)$ & None rejected $e$ & +0.16 & +0.13 \\
\hline 5881.8958 & \pm 0.0004 & 5 & $3(10,10)$ & -0.0004 & .14 & .16 \\
\hline 5944.8344 & 2 & 3 & $(f)$ & +0.0012 & .08 & .19 \\
\hline 6074 & 3 & 4 & $5(I O, I O) ; 1(9, I O) ; 1(I O, 9)$ & None rejected & .18 & .17 \\
\hline 608 & 4 & 4 & $4(10,10) ; 1(9,10)$ & None rejected & .21 & .20 \\
\hline .0600 & 6 & 6 & $2(10,10)$ & +0.0006 & .22 & .25 \\
\hline 4948 & 4 & 5 & $1(10,9) ; 1(9,10) ; 2(10,10)$ & -0.0003 & .16 & .19 \\
\hline 6 & 4 & 5 & $4(I 0,10)$ & -0.0008 & .20 & .18 \\
\hline 6 & 4 & 5 & $1(0,10) ; 1(8,10) ; 2(10,10)$ & +0.0024 & 16 & .15 \\
\hline 6402.2392 & 2 & 3 & (g) & -0.0014 & .16 & .19 \\
\hline
\end{tabular}

4 Particular parts of the table are explained by the following notes:

$a$ The definition of the International Angström Unit is

$$
\text { II. A. }=\frac{\text { wave-length of cadmium red, in dry air at } 15^{\circ}, 760 \mathrm{~mm}(\mathrm{~g}=980.67)}{6438.4696}
$$

(Trans. Int. Solar Union, 2, p. 20; 1907. Astrop. J., 32, p. 216; 1910).

$b$ The probable errors in Column II are obtained by combining the probable errors of the independent determinations. The first probable error in Column III is obtained from the data given in column E $\lambda$, Table II, page 599, vol. 6 of this Bulletin. The other errors in Column III were obtained from corresponding ones in Column II by combining each of these latter with the first one in Column III. The reason for this will be found in a consideration of the remarks under "Reference standards" in the body of this paper.

c In Column IV the boldface figures indicate the number of determinations containing the number of measurements indicated by the accompanying light-faced figures. These light-faced figures, in the order given, indicate, respectively, the number of measurements of the order of interference made in Forms II and III, as illustrated in this Bulletin, 6, 596 .

$d$ The values of Baly (Trans. Roy. Soc. A 202, p. I83; 1904. Also B. A. Report, I905, pp. 105-153), as well as those of Watson (Proc. Roy. Soc. 81, p. $18 \mathrm{r}$; r908), are from grating determinations by the method of interpolation, relative to Kayser's old iron standards. Now, "the differences" between the standards of the old system and those of the new international system "vary irregularly between 0.15 and 0.22 A." (Kayser, Astroph. J., 32, 217.) On this account and since Baly estimated his probable error as $\pm 0.03 \mathrm{~A}$, and Watson only hopes that his error is not greater than the same amount (Proc. Roy. Soc. 81, p. I83), it appears that my values agree with those of Baly and Watson to within the accuracy of their measurements.

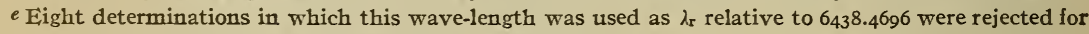
quite adequate reasons. The mean of them is 5852.4848 .

$f 4(I O, I O)$ relative to neon yellow, 5852.4862 . $2(I O, I O)$ relative to cadmium red, 6438.4696 . I6 determinations as $\lambda_{r}$ (see this Bulletin, 6,575 ), relative to 5852.4862 .

$01(7,8) ; 2(5,5)$ relative to cadmium red. 47 determinations as $\lambda_{\text {r }}$ relative to 5852.4862 . 
merely reducing that result to the present definition of the International Ångström Unit. All the other wave-lengths have been determined relative to this yellow neon line as an intermediate standard, assigning it the above value. Also the wave-lengths 5944 and 6402 have been determined directly relative to cadmium red and the results combined with those relative to neon yellow to give the values in the table.

Error of Method.-It should be noted that the method assumes an equal degree of homogeneity in the standard and the unknown. This condition was not sufficiently emphasized in my previous paper. ${ }^{5}$ Occasion is therefore taken here to point out that the method is not applicable except to sufficiently narrow lines. We have in actual practice,

instead of simply

$$
\left(\lambda_{\mathrm{x}}-\frac{\mathrm{W}_{\mathrm{x}}}{2}\right)=\frac{\mathrm{p}_{\mathrm{s}}^{\prime} \mathrm{s}}{\mathrm{p}_{\mathrm{x}}^{\prime}}\left(\lambda-\frac{\mathrm{W}_{\mathrm{s}}}{2}\right)
$$

$$
\lambda_{\mathrm{x}}=\frac{\mathrm{p}_{\mathrm{s}}}{\mathrm{p}_{\mathrm{x}}} \lambda_{\mathrm{s}}
$$

to determine $\lambda_{x}$, where $\lambda_{s}$ and $\lambda_{x}$ are the standard and the unknown wave lengths; $\mathrm{p}_{\mathrm{s}}$ and $\mathrm{p}_{\mathrm{x}}$ are the corresponding measured orders of interference; and $\mathrm{W}_{\mathrm{s}}$ and $\mathrm{W}_{\mathrm{x}}$ are the widths of the lines. From the first equation above we have

$$
\lambda_{\mathrm{x}}-\frac{\mathrm{W}_{\mathrm{x}}}{2}+\frac{\mathrm{p}_{\mathrm{s}}^{\prime} \mathrm{s}}{\mathrm{p}_{\mathrm{x}}^{\prime}} \cdot \frac{\mathrm{W}_{\mathrm{s}}}{2}=\frac{\mathrm{p}_{\mathrm{s}}^{\prime}}{\mathrm{p}_{\mathrm{x}}^{\prime}} \lambda_{\mathrm{s}}
$$

Now, our method actually gives as the computed result the value of the first member of this equation as it is defined by the second member.

Evidently the error of the method is

$$
\frac{\mathrm{p}^{\prime} \mathrm{s}}{\mathrm{p}_{\mathrm{x}}^{\prime}} \cdot \frac{\mathrm{W}_{\mathrm{s}}}{2}-\frac{\mathrm{W}_{\mathrm{x}}}{2}
$$

The value of $\frac{\mathrm{p}^{\prime}}{\mathrm{p}_{\mathrm{x}}^{\prime}}$ in these determinations varies between $0.9 \mathrm{I}$ and I.ro. Examination of these radiations by the echelon, as well as 
by the interferometer, shows that $\mathrm{W}$ for cadmium red is very nearly equal to $\mathrm{W}$ for the neon lines. Moreover, Dr. Nutting concludes from the echelon examination that the value of $\mathrm{W}$ in neither case can exceed $0.002 \mathrm{~A}$. This being true, it is evident that the value of the above expression for error of method must be considerably less than o.oor $\mathrm{A}$, and so is negligible in the present case. ${ }^{6}$ At the same time I take this opportunity of emphasizing the fact that an error will be introduced if the above conditions are not sufficiently fulfilled. ${ }^{7}$ The value of the method for many purposes of interferometry is not invalidated by this consideration.

Discarded Results.-As is almost inevitable in any investigation, some determinations have been.rejected on account of evident or of suspected errors. However, in the case of each wave-length the mean of all rejected determinations has been found. As is shown in Column $\mathrm{V}$ of the table, these means differ from the accepted values in every case but one by a negligible amount.

Assumed Values.-The previous results of Baly and Watson were assumed correct only to within about I. A. This gives a large factor of safety, as will be seen by referring to the accuracy of their values. (See Table, Columns VI and VII and footnote ${ }^{d}$.)

Confirmatory Results.-Determinations of wave-lengths 5944 and 6402 relative directly to cadmium red and indirectly through neon yellow give results agreeing to within a few ten-thousandths of an Ångström Unit, thus confirming the first determined value of the neon yellow relative to cadmium red. Using the present method and my value for neon yellow as a standard, I have also confirmed to within less than o.0oI A, the mean of Lord Rayleigh's results $^{8}$ for helium 5016. However, this result is $0.004 \mathrm{~A}$ less than that of Eversheim. ${ }^{9}$ It may be that my result in this case

\footnotetext{
6 The foregoing discussion is not presented as a complete and rigorous general treatment, but is considered adequate for the present particular case.

${ }^{7}$ Such an error has been found in attempting to determine the yellow helium wave length. It was found that the measured wave length (not corrected for error of method) decreased with increasing current in the lamp. At the same time we have found for the green helium (5015) a value agreeing with that found by Rayleigh, who used the method of diameters.

8 Reduced to International Ångströms. For original data see Phil. Mag. (6), 11, p. 685; rgo6 and (6), 15, p. 548; 1908.

${ }^{9}$ Zs. wiss. Photo, 8, p. 148 ; 1909.
} 
is low, owing to the width of the helium line. (See "Error of Method," in this paper.) In any case my value for neon yellow appears to be confirmed to within the accuracy of the mean of Rayleigh's and Eversheim's results for the helium line. I have not yet obtained satisfactory results for other helium wave-lengths. (See footnote ${ }^{7}$.) They may be taken up again at some future time.

Since completing the work reported here I have determined the wave-length of mercury 5769 relative to our value of neon yellow by an adaptation of Fabry and Perot's method of coincidences. The mean of eight determinations ${ }^{10}$ agrees with Fabry and Perot's value $^{11}$ to within $0.0015 \mathrm{~A}$. If one of these determinations be suppressed because of its wide discrepancy from the others, the mean of the remaining seven is only $0.0002 \mathrm{~A}$ greater than Fabry and Perot's value. This constitutes an indirect confirmation of the correctness of our value for neon yellow independent of our method.

As pointed out in footnote $d$ to the table, our results are in agreement with those of Baly and Watson to within the accuracy of their values.

Accuracy:- The reader is now in possession of the data requisite to form his own estimate of the accuracy of these results. I have recorded the results to eight significant figures, because I believe that at least the neon ratios inter se are accurate to a few units in the eighth place, and these ratios themselves are of some value. The only doubt that has arisen in my mind as to the accuracy relative to cadmium red is that discussed under "Error of Method," above. Relying on the conclusion reached there and the further confirmatory evidence of the determination relative to mercury 5769 , I see no present reason to doubt that the values relative to cadmium red are accurate to about one one-thousandth of an Ảngström unit. However, this investigation appears to be the pioneer attempt to determine the neon wave-lengths to this

\footnotetext{
10 Before perfecting the method of observing coincidences a number of discordant results were obtained. The eight determinations here mentioned were obtained all in succession after making improvements. Since then no others have been made.

11. Reduced to International Ảngströms. A. de Chim. et de Phy. (7), 16, p. 320.
} 
degree of accuracy, and like all pioneer efforts must be regarded as subject to revision. It is not expected that these values will command implicit confidence until confirmed by the results of another observer using another method; and it is hoped that such results will not long be lacking.

The interest and criticism of Drs. Stratton and Nutting, as well as the assistance of Mr. Pidgeon in observing and computing, and the more than ordinary service of Mr. Sperling in not only preparing but also in improving the design of the cadmium lamps, have all been of service in this investigation.

It has not been deemed advisable to encumber this paper with a mass of details. However, such information is recorded and preserved at this laboratory and will gladly be furnished to anyone desiring to examine the work more critically.

WASHINGTON, November 23, I9II. 